\title{
CMEARTicle
}

\section{Sexual matters among teenagers}

Richard Meng Kam Lee $\underline{\text { 1,2 }}^{\text {, MMed, FCFP, Choon How } \underline{\text { How }}^{3,4} \text {, MMed, FCFP, Kumudhini Rajasegaran }}{ }^{5}$, MB BCh BAO, MRCPCH

Emma, a 17-year-old student, arrived at your clinic with her boyfriend. It was her first visit to your clinic and you sensed that she was feeling anxious and afraid. She did not remember when her last menstrual period was, but was otherwise well. She asked you for emergency oral contraception.

\section{WHAT IS SEXUALITY IN TEENAGERS?}

In the complex developmental period of puberty, adolescents experience biophysical changes and adapt themselves to societal and cultural expectations of adulthood. Development of their sexuality is an important biopsychosocial development during this period that, when neglected, may result in unmet sexual and reproductive health needs.

Primary care doctors meet adolescents in the clinic for other acute ailments. Those with a good grasp of the important clinical, legal, social, cultural and educational implications surrounding adolescent sexuality can proactively screen and advise adolescents on their sexual and reproductive health, regardless of sexual activity or marital status. Family doctors can also play an important role as a trusted member of our society in providing adolescents with accurate information about the law, and societal and cultural norms on sexuality. Hence, primary care physicians need to be aware of Singapore's laws on underage sexual activity and its consequences (Box 1). ${ }^{(1)}$

\section{HOW RELEVANT IS THIS TO MY PRACTICE?}

We need to prioritise adolescent sexual and reproductive health because unplanned pregnancy and sexually transmitted infections (STIs) are an important cause of adolescent morbidity. The burden of sexual ill health is not trivial in the local population. In Singapore, the proportion of young people aged 10-19 years diagnosed with an STI has increased by $8 \%$ from 2014 to 2015 , with the ages 15-19 years accounting for more than $90 \%$ of the cases. $^{(2)}$

Patterns of behaviour in adolescence have repercussions across the lifespan. Singapore's efforts in sexual health education have helped to reduce (unplanned) teenage pregnancies and raise educational achievements in women, which have a major impact on future child health outcomes. Teen pregnancy rates in Singapore were reported to be the lowest in 25 years, with only 359 babies born to women aged 19 years and below in 2015. ${ }^{(3)}$ According to the United Nations Convention on the Rights of the Child, 'child' refers to anyone below the age of 18 years unless, under the law applicable to the child, majority is attained earlier. This is the same definition used locally for consultations and referrals to different healthcare institutions.

\section{WHAT CAN I DO IN MY PRACTICE?}

Taking a teenager's sexual health history is not routine for a physiologically oriented healthcare provider within a clinical setting and often does not feature in the list of interview skills that healthcare providers learn. Healthcare providers seeing adolescents should be willing to take a developmentally appropriate psychosocial screen and assessment. HEADSSS, a screening tool to screen for and assess risks, can be used for all adolescents (Box 2). ${ }^{(4)}$ It provides an approach to the adolescent interview, progressing from the least threatening topics to the most personal and sensitive subjects. The acronym stands for the following: home, education/employment/eating, activities, drugs, sexuality, sleep, suicide/depression and safety. The interview format is flexible and can cater to all young people. For the more sensitive questions (i.e. drugs, sexuality, suicide/ depression, safety), it may be timely to remind the youth that your exchange will be confidential. Some approaches that can be used during the psychosocial assessment include (a) painting a scenario, e.g. 'Some of the young people I speak to tell me...'; (b) giving multiple choice answers, e.g. types of alcohol, beer, hard liquor, etc; and (c) using a third-person approach, e.g. 'Does anyone in your family smoke? Do any of your friends smoke? Do you smoke?'.

\section{Before the interview \\ Ensure trust}

To engage the young patient in the consultation process, having trust and confidence in the doctor, clinic and the healthcare system is crucial. If the teenagers do not feel that they can confide in doctors or key people in the system, their issues will stay hidden. Providing a safe environment to discuss and confide in the healthcare professional is the first step towards helping them (Box 3).

\footnotetext{
${ }^{1}$ Woodlands Polyclinic, ${ }^{2}$ Family Medicine Development, National Healthcare Group Polyclinics, ${ }^{3} \mathrm{Care}$ and Health Integration, Changi General Hospital, ${ }^{4} \mathrm{Family}$ Medicine Academic Clinical Programme, SingHealth Duke-NUS Academic Medical Centre, ${ }^{5}$ Adolescent Medicine Service, Department of Paediatrics, KK Women's and Children's Hospital, Singapore Correspondence: Dr Richard Meng Kam Lee, Assistant Director, Family Medicine Development, National Healthcare Group Polyclinics. Richard_Mk_LEE@nhgp.com.sg
} 
Box 1. Local legal statutes and laws on sexual intercourse in teens: ${ }^{(1)}$

Rape

- A man will be guilty of rape if he has vaginal sex with: any woman without her consent; or a girl aged under 14 years, regardless of whether she gave consent (Section 375, Singapore Penal Code). The legal age to have sex in Singapore is 16 years. This means that it is a punishable offence to have sex (whether vaginal, oral or anal) with persons below 16 years of age (Section 376A).

- Offenders aged above 21 years cannot claim that they mistakenly believed the person was not underage as a defence (Section 377D).

\section{Molest (outrage of modesty)}

- The use of the term 'outrage of modesty' originates from Section 354 of the Penal Code, which criminalises the 'assault or use of criminal force to a person with intent to outrage modesty'. The use of criminal force is a key element. Hence, simply staring at someone inappropriately would not fall afoul of this section, which has mainly been applied to molestation cases.

- The Penal Code does not expressly define 'modesty'. Therefore, what constitutes an outrage to modesty may vary over time and according to the context in which the incident occurs, as well as the race or religion of the victim.

\section{Sexual grooming of minor under 16}

- Sexual grooming occurs when an offender aged $\geq 21$ years meets another person aged $<16$ years with the intention of having sex, where the offender had previously met or communicated with him/her at least twice.

- Sexual offenders often 'groom' children through bribery, tricks, threats and emotional manipulation to force children to cooperate with the abuse.

\section{Commercial sex with minor}

- Commercial sex (i.e. paying for sex) with persons aged under 18 years is a punishable offence (Section 376B).

- Singapore citizens or permanent residents who engage in commercial sex with persons aged $<18$ years will still be liable even if the acts were done outside of Singapore (Section 376C).

\section{Sexting}

- Sending sexually suggestive messages to a person aged under 16 years may result in a prosecution (Section 7, Children and Young Persons Act; Section 76E, Penal Code).

- Punishment and sentencing of all sexual offences may be affected by aggravating factors such as the offender being in a position of trust; the serial and repeated nature of the offence; harm caused to the victim; transmission of sexual diseases; and premeditation of the offence.

\section{Belief systems}

It is important to recognise that the healthcare provider's own set of beliefs, based on one's knowledge, experience and level of tolerance in dealing with particular situations, will set the standard in providing developmentally appropriate healthcare to youth. ${ }^{(5)}$

\section{Assumptions}

Based on particular individual belief systems, many of us have some assumptions about young people; for example, that they live in a home with two parents, that they go to school and get along with peers and teachers, and that they are heterosexual. As healthcare professionals, it is important to ask non-judgemental questions in a respectful manner and not to assume.
Box 2. HEADSSS comprehensive adolescent psychosocial screening interview:

Home (and relationships)

-Who lives with the patient? Where? Does the patient have his/her own room? What are the relationships like at home?

-What do parents and relatives do for a living?

- Ever institutionalised? Incarcerated?

- Recent moves, e.g. runaway episodes

\section{Education/employment/eating}

- School/grade performance: any recent change? Any dramatic deterioration? Any year repeated/class failed?

- Favourite and worst subject

- Suspensions or termination, dropping out history

- Any current employment?

- Future education/employment plans/goals

- Relations with teachers and school attendance

- Bullied/bullies

-Worried about weight or body shape?

- Any change in weight recently?

- Been on a diet?

\section{Activities}

-With peers ('What do you do for fun? Where and when?')

- With family

- Club/school functions

- Sports, regular exercise

- Religious attendance and club projects

- Hobbies and other home activities. Reading for fun: what?

Television: how much weekly? Favourite show? Favourite music?

- Does patient have car, use seatbelts?

- History of arrests, acting out, crime

Drugs

- Used by peers, patients (including alcohol and cigarettes) and family members?

- Amounts, frequency, patterns of use/abuse and car use while intoxicated

- Source: how is it paid for?

Sexuality

- Orientation

- Degree and types of sexual experiences and acts

- Number of partners

- History of pregnancy/abortion

- Sexually transmitted diseases: knowledge and prevention

- Contraception

\section{Suicide/depression/sleep}

- Sleep disorders (usually delay in falling asleep or early/frequent waking, greatly increased sleep and complaints of increasing fatigue)

- Appetite/eating behaviour changes

- Feeling bored?

- Emotional outbursts and highly impulsive behaviour?

- History of withdrawal/isolation?

- Hopeless/helpless feelings? History of past suicide attempts, depression, psychological counselling

- History of depression/suicide in family or peers

- History of drug/alcohol abuse, acting out/crime, recent change in school performance

- History of recurrent serious 'accidents'

- Psychosomatic symptomatology

- Suicidal ideation (including significant current and past losses)

- Decreased affect on interview, avoidance of eye contact

\section{Safety}

- Do you feel safe at home/school?

- Ever felt unsafe when online or using the phone?

- Feel unsafe when showering or using bathrooms?

- Feel uncomfortable with friends or close contacts? 
Box 3. A framework for working with young people:

- Be empathic, respectful and non-judgemental

- Understand confidentiality and consent issues

- Understand adolescent development

- Recognise the importance of privacy

- Be vigilant with boundaries

- Provide a safe environment

- Understand the link between physical and emotional well-being

- Understand that family, school and peers are key agents of socialisation

- Have good communication skills

\section{Starting the interview}

When starting the interview, physicians should (a) set the stage by introducing yourself to the youth and the parents or caregivers (when present). You should also introduce yourself to the young person first. (b) Ask either the teenager and/or parents to explain their understanding of confidentiality or confidential healthcare. (c) After the youth have given their views, acknowledge their responses and add your views accordingly, explaining and listing the exceptions to confidentiality.

\section{Wrapping up the interview}

When ending interviews with teenagers, you can:

- $\quad$ Ask them to sum up their life in one word or to give the overall 'weather report' for their life.

- $\quad$ Ask them to tell you whom they can trust and confide in if there are problems in their lives, and why they trust that person. This is especially important if you have not already identified a trusted adult in the family.

- Give them an opportunity to express any concerns you have not covered.

- $\quad$ For teenagers who demonstrate significant risk factors, relate your concerns. Ask if they are willing to change or are interested in learning more about ways to deal with their problems. This leads to a discussion of potential follow-up and therapeutic interventions. Many adolescents do not recognise dangerous lifestyle patterns because they see their activities as solutions and not problems. Your challenge lies in helping the adolescent to see health risktaking behaviours as problems and helping to develop better strategies for dealing with them.

- If the adolescent's life is going well, say so. In most cases, you can identify strengths and potential or real weaknesses, and discuss both in order to offer a balanced view.

- Ask if there is any information you can provide on any of the topics you have discussed, especially health promotion. Try to provide whatever educational materials young people are interested in.

\section{Ethics in adolescent sexual and reproductive health}

Ethical principles of autonomy, beneficence, non-maleficence and justice in adolescent sexual and reproductive health generally deal with confidentiality, consent (i.e. assessment of capacity, Gillick competency and Fraser guidelines), best interest and advocacy (including child protection issues).

\section{Confidentiality}

It is not reasonable to expect an adolescent to discuss sensitive and personal information unless confidentiality can be assured. All adolescents and caregivers present (commonly a parent or both parents) should be told about confidentiality at the beginning of the interview.

The right to confidentiality exists independently of the competence to consent to treatment and encourages mutual trust. Exceptions can only be made when there is further risk of harm. For the competent young person, confidentiality should not be kept when there is (a) disclosure of a history of or current sexual abuse; (b) disclosure of current or recent suicidal thoughts or significant self-harming behaviour; and (c) disclosure of homicidal intent. For the incompetent young person, this is any situation in which there is a significant risk of harm to the adolescent or to others.

Confidentiality matters to young people. One-quarter of young people do not trust health professionals to keep their information confidential from their parents, while one-fifth report not sharing important information with doctors because of fear that their parents would find out. ${ }^{(6)}$ Young people (and their parents) would like to discuss more sensitive topics with their doctor, and this exists independently of their competence to consent to treatment.

\section{Consent}

Autonomy is the 'capacity to think, decide and act on one's free initiative'. Every adult has the capacity and competence to decide whether to consent to, or refuse, proposed medical intervention unless it is shown that they cannot understand information presented in a clear way.

Adolescents' right to make decisions for themselves depends on their ability to do so and is legally defined by their capacity to perform the task in question. Some tasks are age-defined, such as driving a car or buying liquor or cigarettes. The age of consent is termed the age of majority and competence is assumed from persons above this age (21 years in Singapore, 18 years in England). In Singapore, the legal age to enter into a contract is 21 years and to consent to procedures is 18 years. For those aged 16 years and below, Gillick competency (i.e. capacity to consent) can be applied. Box 4 summarises the law in Singapore with regard to age and consent. ${ }^{(7)}$

Gillick competency and the Fraser guidelines arose from a legal case that looked specifically at whether doctors should be able to give contraceptive advice or treatment to those aged under 16 years without parental consent. Since then, they have been more widely used to help assess whether a child has the maturity to make their own decisions and understand the implications of those decisions. Gillick competency is an objective test of competence that identifies adolescents under the age of 16 years who have the capacity to consent to medical examination and treatment. This is provided that they can demonstrate sufficient maturity and intelligence to understand and appraise the nature and implications of the proposed treatment, including the risks and alternative courses of action. The Fraser guidelines apply 
specifically to contraceptive advice. They include the necessity of ensuring that the girl understands the advice given to her with respect to contraception, and also concentrate on the desirability of parental involvement and the enhanced risks of unprotected sex.

The general criteria for testing competence is a young person's ability to: (a) understand simple terms and the nature, purpose and

\section{Box 4. Age and consent in Singapore law: ${ }^{(7)}$ \\ Under the Penal Code (Chapter 224, 2008)}

- Consent by parents and guardians needed for children $<12$ years (Section 89)

-Valid consent by persons aged $>18$ years (Section 87)

- Acts done in good faith for the benefit of a person without consent (Section 92)

Under the Civil Law (Amendment) Act (Chapter 43, 2009)

- Confers contractual capacity to persons $\geq$ aged 18

Under the Children and Young Persons Act (Chapter 38)

- Juvenile: a person aged $\geq 7$ years and $<16$ years

- Child: a person aged $<14$ years

- Young person: a person $\geq 14$ years and $<16$ years

Summary

- Ages < 14: needs consent from a person of parental responsibility

- Ages 14-16: Gillick competence may apply

- Ages 16-18: presumed to be able to consent to medical treatment unless proven otherwise

- Age $\geq 18$ : may consent to necessary medical treatment

- Age 21: age of majority necessity for proposed treatment; (b) understand benefits, risks and alternatives, and the effect of non-treatment; (c) believe that the information applies to them; (d) retain information long enough to make a choice; and (e) make a choice free from pressure.

\section{Best interest and advocacy}

Ethically, health professionals have a duty to respect the rights of adolescents provided that the consequence does not result in harm to the adolescent or to others, and the patient's best interest is paramount. If young people lack the competence to make decisions, a person with parental responsibility has legal power to consent on their behalf, which is in the minor's best interest. The physician should always respond to their concerns about bullying, abuse, harassment or violence. However, education on violence and abuse prevention issues requires special attention to safe environments, as it may trigger memories of personal abuse or elicit strong emotions of previous loved ones.

\section{Protection and contraception}

Among young teenagers and adolescents, some of the perceived barriers towards using contraceptives may include concerns about confidentiality and parental notification, cost of medications and misguided ideas about the risk of getting pregnant and contraindication or effectiveness of contraceptive pills. They may also have certain knowledge deficits on what to do regarding

\section{Box 5. Contraceptive methods:} Emergency contraception

- Emergency contraception ('morning after' pill) may prevent pregnancy if taken within 3 days (levonorgestrel) or within 5 days (ulipristal acetate) of unprotected sex.

- In Singapore, emergency contraception is only available with a prescription after seeing a Singapore Medical Council-registered medical doctor. The patient must also be aged $\geq 16$ years, the minimum age for sexual consent in the Singapore Penal Code.

- Oral contraceptives (regular birth control pills) can be prescribed as an alternative emergency contraception. In these 28-day packs (e.g. Microgynon, Microgynon-30 or Nordette), only the first 21 pills can be used. 4 pills of the pack are taken as soon as possible and within 120 hours of unprotected sex.

- The patient who is seeking emergency contraception sees the possible risk of pregnancy as a negative outcome and is fearful of the unknown, which may provide the physician with an opportunity to counsel and educate her on safe sex and sexual practice.

- Other contraception methods such as insertion of an intrauterine device and long-acting progesterone injections, hormonal implants and barrier methods may be discussed with the patient on their own individual merits but will not be further discussed in this paper.

- Regarding the choice of future contraception, the effectiveness and safety of the contraceptive methods must be explained to the patient, including their duration of action, reversibility and the ability to discontinue use. Any possible side effects or possible contraindications (e.g. diabetes mellitus, systemic lupus erythematosus, hereditary blood disorders, headaches) require counselling. The final choice should be a shared decision between the patient and the physician.

\section{Barrier contraceptives}

- The use of condoms as a barrier method is the contraception of choice to prevent potential sexually transmitted infections (STIs) and pregnancy. The partner's preference should also be taken into account.

\section{Combination oral contraceptive pills}

- These are usually taken daily for 21 consecutive days followed by 7 days of no pill or placebo pills, during which menstrual bleeding occurs.(11) - Some of the non-contraceptive benefits are improved bone density and protection against ovarian cancer, endometrial cancer, ectopic pregnancy, benign breast disease, acne and iron efficiency. ${ }^{(12)}$

- However, they are not advisable for teenagers who cannot remember or stick to a schedule of routine medications. The physician needs to advise on the proper consumption of oral contraceptive pills and the strategies to be used when one misses a pill.

\section{Abstinence}

- The patient needs to be aware of the dangers of being infected with STIs and that the only foolproof method of not contracting an STI is abstinence.

- If not detected and treated appropriately, some of the common STIs (e.g. gonorrhoea, syphilis, chlamydia, HIV, hepatitis B, warts) may lead to the complications of pelvic inflammatory disease and infertility.

- Opportunistic screening (i.e. Pap smear and vaccination) may be offered to patients for hepatitis B virus and human papillomavirus. 
sexual matters and fear of confronting these matters with their parents and healthcare providers. ${ }^{(8,9)}$ Establishing trust and respect with your young teenaged patient, while reassuring her about the confidentiality of the matter is the start of a good doctor-patient relationship. Boundaries and limits of patient confidentiality should be discussed with the patient as well, especially if potential harm may come to her.

Different types of contraceptive methods are available for adolescents and young teenagers (Box 5). Hence, the attending physician should counsel the patient and explain the suitability of the contraception prescribed. ${ }^{(10)}$

\section{Handing off and closing}

Finally, the attending doctor must acknowledge that the feeling of sex can be new, exciting and confusing. Patients may get into difficult situations if they are under the influence of alcohol or drugs. Sex that is forced upon a person who does not want to participate is called rape or sexual assault. If the patient does not want sex and is unsure, the partner should respect her decision and stop at once. It is important to postpone sexual activity until patients are emotionally mature and understand that sexual activity affects both the physical and mental health of both parties involved. Patients should be encouraged to speak to a trusted adult or counsellor if they require more information, and a follow-up review should be scheduled in six weeks to review previous matters discussed and any further issues.

The family physician should be sensitive to the patient's emotions and concerns. If necessary, a colleague of the same gender as the patient can be sought if the patient is not comfortable with discussing certain issues and sharing personal details.

\section{WHEN SHOULD I REFER TO A SPECIALIST?}

Patients should be referred to a specialist if there is suspicion of sexual abuse or violence, risk of self-harm, presence of teenage pregnancy, newly diagnosed sexual transmitted infections, or multiple risk-seeking behaviours in a teenager.

\section{TAKE HOME MESSAGES}

1. HEADSSS (home, education/employment/eating, activities, drugs, sexuality, sleep, suicide/depression and safety) is a screening tool that can be used to screen for and assess risks in adolescents.

2. Patterns of behaviour in adolescence have repercussions across the lifespan. Adolescent patients may keep their issues hidden if they do not have trust and confidence in their doctor during the consultation in the clinic.

3. The healthcare provider's own set of beliefs influences the approach to providing the most developmentally appropriate care to the patient.

4. Adolescents may view risk-seeking lifestyle patterns as appropriate behaviours. The clinical challenge lies in helping the adolescent to see health risk-taking behaviours as issues and helping them to develop less harmful alternatives and strategies.
5. Primary care physicians should have a heightened awareness of and always respond to the adolescent's concerns about bullying, abuse, harassment or violence in a safe environment.

6. In terms of ethics, healthcare professionals have a duty to respect the rights of adolescents, provided that the patient's best interests are carried out. They should be familiar with the relevant legal statutes under our Penal Code, including sexual grooming of minors and sexting, especially healthcare professionals providing care to adolescents.

You counselled Emma about the side effects of emergency contraception. You also gave her sexual health advice and performed screening for sexually transmitted illnesses, using the Fraser guidelines to assess her competence to consent to contraceptive treatment and receive sexual health advice. You encouraged Emma to speak to a trusted adult or counsellor if she needed more information, and scheduled a follow-up review in six weeks.

ABSTRACT In the complex developmental period of puberty, adolescents experience biophysical changes and adapt to societal and cultural expectations of adulthood. Development of their sexuality is an important biopsychosocial change during this period that, when neglected, may result in unmet sexual and reproductive health needs. Patterns of behaviour in adolescence have repercussions across the lifespan. HEADSSS (home, education/employment/eating, activities, drugs, sexuality, sleep, suicide/depression and safety) is a systematic clinical screening tool for use with adolescents. Adolescents may view risk-seeking lifestyle patterns as appropriate behaviours, and physicians can help them recognise the risks and develop less harmful alternatives and strategies. Personal biases should not affect healthcare providers' duty to respect the rights of adolescents and ability to provide developmentally appropriate care. Healthcare professionals should be familiar with the relevant legal statutes in Singapore and refer suspected sexual abuse or violence, risk of self-harm, teenage pregnancy, newly diagnosed sexual transmitted infections or multiple risk-seeking behaviours for further evaluation and help.

Keywords: adolescent, psychosexual behaviour, sexual behaviour, sexual health

\section{REFERENCES}

1. Singapore Legal Advice. What is the Legal Age For Sex in Singapore? What Are Some Common Sexual Offences in Singapore? Available at: https://singaporelegaladvice. com/law-articles/legal-age-for-sex-in-singapore/. Accessed August 9, 2019.

2. Poon $\mathrm{CH}$. More young people in Singapore get sexual infections. The Straits Times 2017 Jun 18. Available at: https://www.straitstimes.com/singapore/health/ more-young-people-get-sexual-infections. Accessed August 17, 2019.

3. Tan T. Big drop in number of teen pregnancies. The Straits Times 2016 Feb 22. 
Available at: https://www.straitstimes.com/singapore/big-drop-in-number-ofteen-pregnancies. Accessed August 17, 2019.

4. Goldenring JM, Cohen E. Getting into adolescent heads. Contemporary Pediatric $1988 ; 5: 75$

5. Lim C. Dealing with differing personal beliefs and values. SMA News 2019 51(6):20-1.

6. Farrant B, Watson PD. Health care delivery: perspectives of young people with chronic illness and their parents. J Paediatr Child Health 40; 175-9.

7. Thirumoorthy T, Loke P. Consent in Medical Practice 3 - Dealing with Person Lacking Capacity. In: SMA News [online]. Available at: https://www.sma.org. sg/UploadedImg/files/Publications\%20-\%20SMA\%20News/4508/CMEP.pdf. Accessed August 18, 2019

8. Secura GM, Madden T, McNicholas C, et al. Provision of no-cost, long-acting contraception and teenage pregnancy. N Engl J Med 2014; 371:1316-23.
9. Oringanje $\mathrm{C}$, Meremikwu MM, Eko $\mathrm{H}$, et al. Interventions for preventing unintended pregnancies among adolescents. Cochrane Database Syst Rev 2009; (4):CD005215.

10. World Health Organization. Implementation guide for the medical eligibility criteria for contraceptive use and selected practice recommendations for contraceptive use guidelines: a guide for integration of the World Health Organization (WHO) Medical eligibility criteria for contraceptive use (MEC) and Selected practice recommendations for contraceptive use (SPR) into national family planning guidelines. Available at: https://apps.who.int/iris/bitstream/ha ndle/10665/272758/9789241513579-eng.pdf. Accessed August 18, 2019.

11. Committee on Adolescence. Condom use by adolescents. Pediatrics 2013; 132:973-81.

12. Hatcher RA, Trussel J, Nelson AL, et al. Contraceptive Technology. 20th ed. New York: Ardent Media, Inc, 2012 


\section{SINGAPORE MEDICAL COUNCIL CATEGORY 3B CME PROGRAMME}

\section{(Code SMJ 201909A)}

1. Adolescents develop their sexuality as they go through biophysical changes in puberty and adapt themselves to societal and cultural expectations of adulthood.

2. Primary care doctors with a good grasp of the important issues surrounding adolescent sexuality can proactively screen and advise adolescents on their sexual and reproductive health, regardless of sexual activity or marital status.

3. Under Section 375 of the Penal Code, a man will be guilty of rape if he has vaginal sex with a girl aged under 14 years, regardless of her consent.

4. Sexual offenders aged above 21 years who 'groom' children aged under 16 years through more than two encounters, using bribery, tricks, threats and emotional manipulation to force them to cooperate, with the intention of having sex, would not have broken the law if they did not have sex with the minor.

5. In Singapore, the proportion of young people aged 10-19 years diagnosed with a sexually transmitted infection (STI) decreased by 8\% from 2014 to 2015.

6. Teenage pregnancy rates in Singapore were reported to be the lowest in 25 years, with 359 babies born to women aged 19 years and under in 2015.

7. HEADSSS, a screening tool designed for high-risk adolescents, systematically progresses from common threatening topics to the most personal and sensitive subjects.

8. The acronym HEADSSS stands for home, education/employment/eating, activities, drugs, sexuality, sleep, suicide/depression and safety.

9. Key qualities for working with young people include: being empathic, respectful and non-judgemental; respecting privacy, confidentiality and consent issues; and understanding that family, school and peers are key agents of socialisation.

10. The clinician's challenge lies in helping adolescents to recognise dangerous lifestyle patterns, because adolescents can see their activities as solutions instead of problems.

11. Boundaries and limits of patient confidentiality, even with mentally competent young people, should not be kept when dealing with disclosure of past or current sexual abuse, current or recent self-harm and suicidal thoughts, or homicidal intent.

12. Gillick competency and the Fraser guidelines arose from a legal case that involved whether doctors should be able to give contraceptive advice or treatment to those under 16 years of age without parental consent.

13. Emergency contraception may prevent pregnancy if taken as soon as possible and only within three days of unprotected sex.

14. In Singapore, emergency contraception is only available with a prescription signed by a Singapore Medical Council-registered medical doctor, and only for patients aged 16 years and above.

15. The contraception of choice for young adults should be a barrier method such as condoms, as it can also reduce the risk of potential STIs.

16. For 28-day oral contraceptives (i.e. regular birth control pills), taking four of the last seven pills can be prescribed as an alternative emergency contraception.

17. For long-term contraception in adolescents aged above 16 years, the effectiveness and safety of each method should be explained and a shared decision reached between patient and physician.

18. The attending doctor should acknowledge that the feeling of sex can be new and confusing, and advise or refer if the patient has difficulties handling situations or people.

19. A follow-up review six weeks after any emergency contraceptive is a good practice to review issues and previous matters discussed.

20. A specialist referral is indicated if there is suspected sexual abuse, risk of self-harm, teenage pregnancy or newly diagnosed sexually transmitted infections.

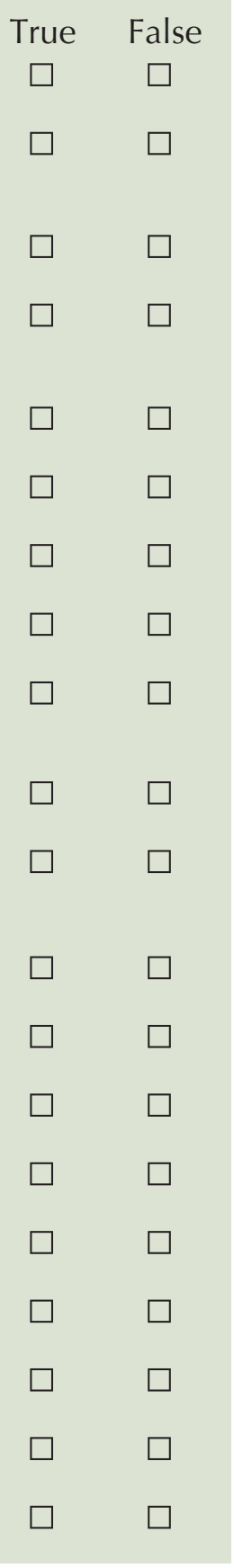

\section{Doctor's particulars:}

Name in full:

MCR no:

Specialty:

Email:

\section{SUBMISSION INSTRUCTIONS}

Visit the SMJ website: http://www.smj.org.sg/current-issue and select the appropriate quiz. You will be redirected to the SMA login page.

For SMA member: (1) Log in with your username and password (if you do not know your password, please click on 'Forgot your password?'). (2) Select your answers for each quiz and click 'Submit'.

For non-SMA member: (1) Create an SMJ CME account, or log in with your SMJ CME username and password (for returning users). (2) Make payment of SGD 21.40 (inclusive of $7 \%$ GST) via PayPal to access this month's quizzes. (3) Select your answers for each quiz and click 'Submit'.

RESULTS:

(1) Answers will be published online in the SMJ November 2019 issue. (2) The MCR numbers of successful candidates will be posted online at the SMJ website by 8 November 2019. (3) Passing mark is $60 \%$. No mark will be deducted for incorrect answers. (4) The SMJ editorial office will submit the list of successful candidates to the Singapore Medical Council. (5) One CME point is awarded for successful candidates. (6) SMC credits CME points according to the month of publication of the CME article (i.e. points awarded for a quiz published in the December 2017 issue will be credited for the month of December 2017, even if the deadline is in January 2018).

Deadline for submission (September 2019 SMJ 3B CME programme): 12 noon, 1 November 2019. 